\title{
A novel polypectomy technique: the "ropeway method" for resection of large pedunculated polyps
}

Pedunculated polyps at narrow or sharply bending areas in the colonic lumen can be challenging for endoscopic resection [15]. We report a newly invented technique, the "ropeway method," to improve endoscopic resection of pedunculated polyps assisted by traction.

A 74-year-old woman was found to have a $3-\mathrm{cm}$ pedunculated lesion in the sigmoid colon. We attempted to ligate the base of the stalk with an endoloop (MAJ-254; Olympus, Tokyo, Japan) before endoscopic resection. However, this proved impossible because the head of the polyp occupied the entire lumen and the base could not be identified. We performed this new method using two endoloops ( $\vee$ Video 1 ; $>$ Fig. 1). First, the stalk near the head was ligated by an endoloop ( Fig.2a), and a clip with a line was attached to the endoloop to apply traction. After the colonoscope was completely withdrawn, a transparent hood was attached to the tip of the colonoscope to secure the view. An additional endoloop was inserted through the working channel and the tip of the endoloop protruded slightly to make a small loop. The line connected to the lesion was passed through this loop. Reinserting the colonoscope while pulling distally on the line led the endoloop to the exact location on the base with the line appropriately stretched ( Fig.2 b). In the same way, the snare wire was delivered between the two endoloops and the stalk was cut with electrocautery under direct vision ( $\vee$ Fig. 2 c). We confirmed that the remaining stalk was securely ligated by the second endoloop ( $\boldsymbol{F}$ Fig. $\mathbf{2}$ d). The resected specimen was easily retrieved by pulling the line. Histological study showed a tubular adenoma with low-grade dysplasia.

The "ropeway method" enables safe and precise removal of the entire lesion and is a promising option for pedunculated lesions in difficult locations.

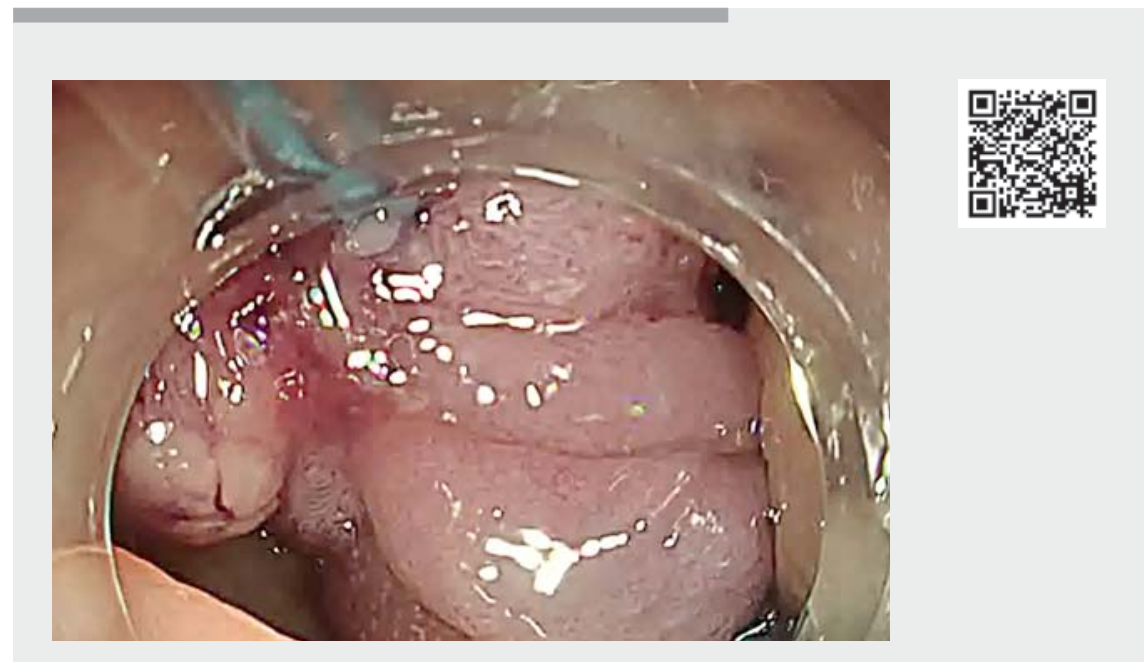

Video 1 A novel polypectomy technique, the "ropeway method" for resecting a large pedunculated polyp in a difficult location.
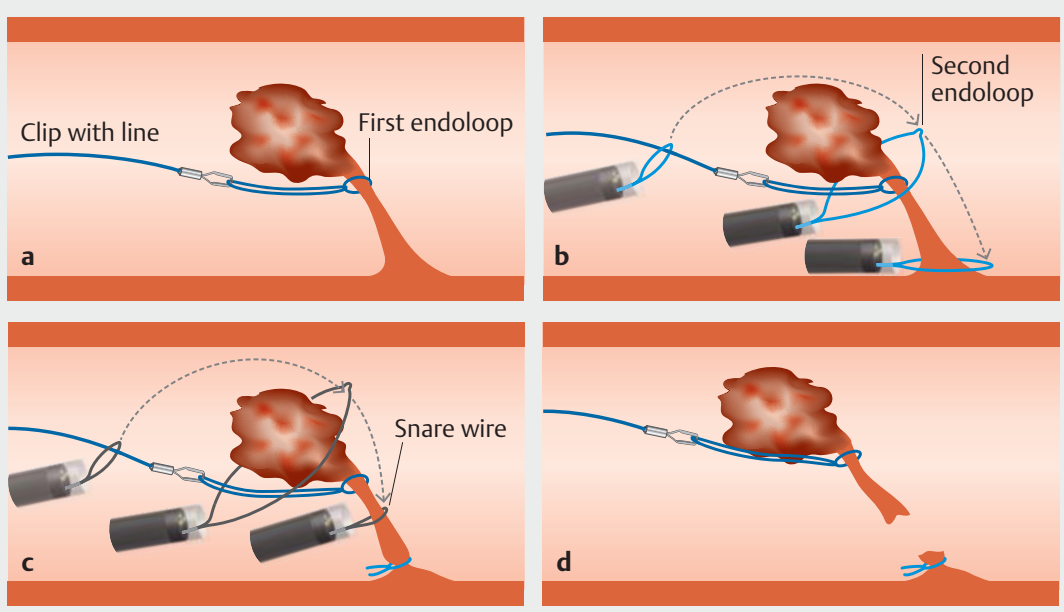

- Fig. 1 a-d Schema of the ropeway method using endoloops: a first, a clip with a line grasps the endoloop ligating the stalk near the head; $\mathbf{b}$ while the line is being pulled distally, a second endoloop is delivered to the base along the line and is tightly ligated; $c$ finally, the snare wire is delivered between the two endoloops ligating the stalk, and the stalk is cut between the endoloops; $\mathbf{d}$ the resected specimen is easily retrieved by pulling the line.

Endoscopy_UCTN_Code_TTT_1AQ_2AD

\section{Competing interests}

The authors declare that they have no conflict of interest. 

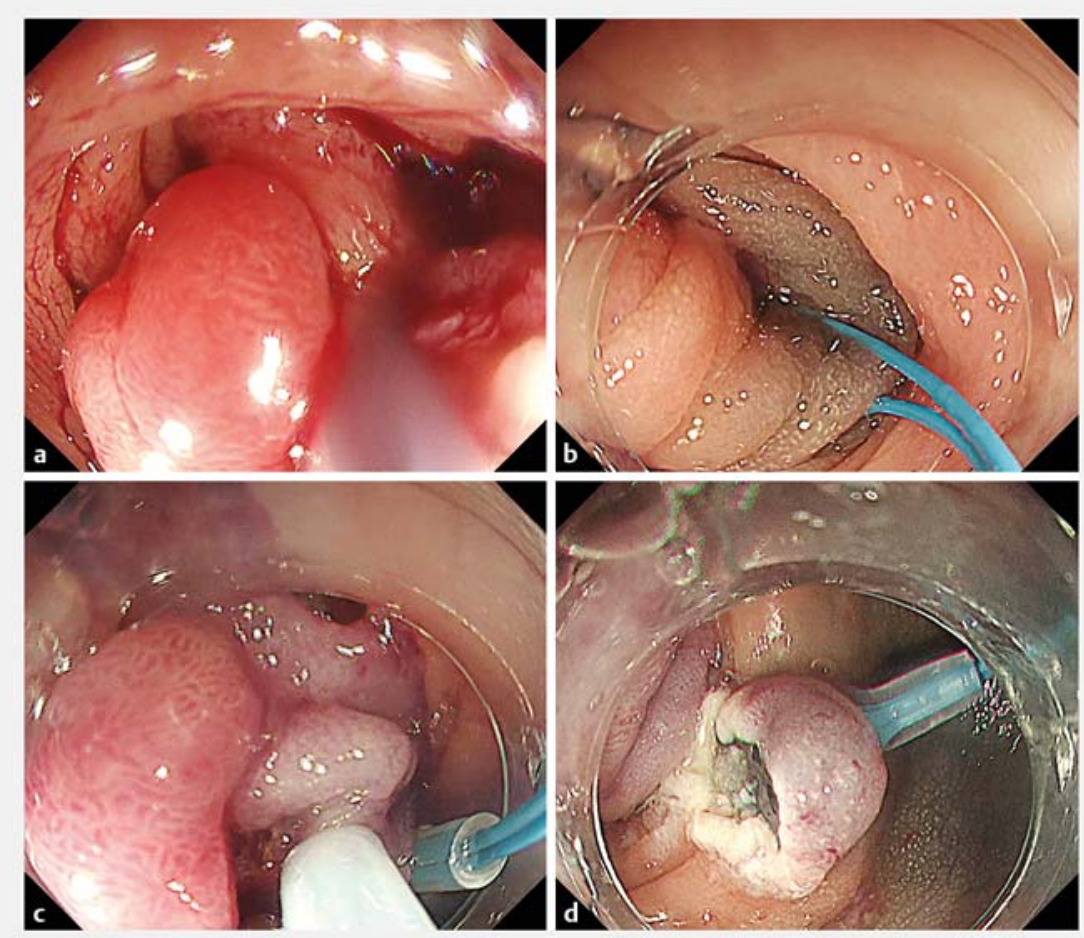

Fig. 2 a-d Endoscopic views showing: a the stalk near the head ligated by an endoloop; b an additional endoloop placed at the stalk base while traction was applied to the line; c the snare wire delivered between two endoloops; $\mathbf{d}$ the remaining stalk tightly ligated by the second endoloop.

The authors

Daiki Nemoto ${ }^{1}$, Yuki Nakajima ${ }^{1}$, Yosuke Takahata', Kohei Suzuki', Masato Aizawa', Alan Kawarai Lefor ${ }^{2}$, Kazutomo Togashi ${ }^{1}$

1 Division of Endoscopy, Fukushima Medical University Aizu Medical Center,

Aizuwakamatsu, Japan

2 Department of Surgery, Jichi Medical University, Shimotsuke, Japan

\section{Corresponding author}

\section{Daiki Nemoto, MD, PhD}

Department of Coloproctology, Aizu Medical Center Fukushima Medical University,

21-2 Maeda, Tanisawa, Kawahigashi, Aizuwakamatsu-city, Fukushima 969-3492, Japan

nemotoda@fmu.ac.jp

\section{References}

[1] Brandimarte G, Tursi A. Endoscopic snare excision of large pedunculated colorectal polyps: a new, safe, and effective technique. Endoscopy 2001; 33: 854-857

[2] lishi H, Tatsuta M, Narahara $\mathrm{H}$ et al. Endoscopic resection of large pedunculated colorectal polyps using a detachable snare. Gastrointest Endosc 1996; 44: 594-597

[3] Kouklakis G, Mpoumponaris A, Gatopoulou $A$ et al. Endoscopic resection of large pedunculated colonic polyps and risk of postpolypectomy bleeding with adrenaline injection versus endoloop and hemoclip: a prospective, randomized study. Surg Endosc 2009; 23: 2732-2737

[4] Takita M, Sakai E, Muramoto T et al. Traction-assisted colorectal endoscopic submucosal dissection using an endoloop for large semipedunculated lesions. Endoscopy 2020; 52: E279-E280
[5] Hu X, Yang XD, Zhang YH et al. Prefixation with clip-anchored endoloop: a novel method facilitating endoscopic resection of a giant duodenal polyp with thick stalk. Endoscopy 2021; 53: E87-E89

Bibliography

Endoscopy 2022; 54: E534-E535

DOI 10.1055/a-1669-8307

ISSN 0013-726X

published online 15.11.2021

(c) 2021. Thieme. All rights reserved. Georg Thieme Verlag KG, Rüdigerstraße 14, 70469 Stuttgart, Germany

\section{ENDOSCOPY E-VIDEOS}

https://eref.thieme.de/e-videos

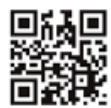

Endoscopy E-Videos is an open access online section, reporting on interesting cases and new techniques in gastroenterological endoscopy. All papers include a high quality video and all contributions are freely accessible online. Processing charges apply (currently EUR 375), discounts and wavers acc. to HINARI are available.

This section has its own submission website at

https://mc.manuscriptcentral.com/e-videos 